\title{
Gel-sol synthesis and aging effect on highly crystalline anatase nanopowder
}

\author{
SHARIF SHAHINI, MASOUD ASKARI and S K SADRNEZHAAD* \\ Department of Materials Science and Engineering, Sharif University of Technology, P.O. Box 11365-9466, Tehran, Iran
}

MS received 11 February 2011; revised 27 April 2011

\begin{abstract}
Highly crystalline $\mathrm{TiO}_{2}$ anatase nanoparticles were synthesized via gel-sol method by using titanium isopropoxide and triethanolamine. The products were characterized by $\mathrm{X}$-ray diffraction, transmission electron microscopy, thermogravimetric/differential thermal analysis and nitrogen gas absorption methods. The particle size ranged from 7 to $24 \mathrm{~nm}$ having specific surface area of 64 to $220 \mathrm{~m}^{2} / \mathrm{g}$. Selective $\mathrm{Ti}(\mathrm{OH})_{4}$ gel specifications and hydrothermal test conditions resulted in thermodynamically-stable phase-formation. Aging at $130^{\circ} \mathrm{C}$ for $4 \mathrm{~h}$ resulted in particle size of $7 \mathrm{~nm}$; while at 130 and $160^{\circ} \mathrm{C}$ for $12 \mathrm{~h}$ resulted in 12 and $21 \mathrm{~nm}$, respectively.
\end{abstract}

Keywords. Gel-sol; anatase; titania; nanoparticles; aging.

\section{Introduction}

Recently, utilization of $\mathrm{TiO}_{2}$ nanocrystals in optical, electrical, photocatalytic and pigment has received considerable attention. Superior physicochemical behaviour, relatively low-cost and easy handling are some of their advantages. $\mathrm{TiO}_{2}$ properties are strongly related to phase structure, morphology and particle size distribution (Hoffmann et al 1995; Fujishima et al 2000; Diebold 2003; Chen and Mao 2007). $\mathrm{TiO}_{2}$ photocatalytic performance is especially critically affected by its particle size. The monodisperse $\mathrm{TiO}_{2}$ nanoparticles of $\mathrm{TiO}_{2}$ also exhibit photocatalytic effect (Almquist and Biswas 2002).

Titanium dioxide has three principal crystallographic structures called anatase (tetragonal), rutile (tetragonal) and brookite (orthorhombic). The most stable phase is rutile; whereas anatase is a metastable phase at ambient temperature. The photo-activity of the latter is at the same time generally superior to that of the former. High temperature photocatalysis applications of $\mathrm{TiO}_{2}$ nanoparticles demand, therefore, anatase thermal stability not to convert into the rutile phase (Hoffmann et al 1995; Cappelletti et al 2008).

Sol-gel is a widely used technique for production of titanium dioxide nanopowders of amorphous structure. For improving crystallinity, post-calcination is generally required. High-temperature treatment results in size-increment and agglomeration (Kim et al 1999; Song and Pratsinis 2001; Sivakumar et al 2002; Tang et al 2002; Phonthammachai et al 2003; Chen and Mao 2007). Hydrothermal processing is another method practised by many researchers as a common simple procedure capable of producing inexpensive

\footnotetext{
*Author for correspondence (sadrnezh@ sharif.edu)
}

photocatalytic pure nanopowder (Yanqing et al 2000; Byrappa and Adschiri 2007).

Gel-sol method is a newly developed technique used for production of large quantities of nanoparticles (Sugimoto et al 1998; Itoh and Sugimoto 2003). Sugimoto et al (1998) spent 4 days conducting experiments to produce $\mathrm{TiO}_{2}$ nanoparticles of suitable specifications. A highly viscous gel (like metal hydroxide gel) donates the network required for nuclei containment, product protection from coagulation and agglomeration, prevention of particle growth and protection of metal and/or hydroxide ions from precursor monomers release even at highly concentrated conditions. The nanoparticles obtained have high monodispersity, geometric consistency and diversity of shape (Sugimoto and Sakata 1992; Hosokawa et al 2007). On completion of nanoparticles formation, the gel-phase gradually disappears while leaving a smooth homogeneous sol-phase consisting of uniform nanoparticles.

In this paper, highly-crystalline pure anatase nanoparticles synthesized by the newly developed gel-sol method is illustrated. Substantial reduction in the synthesis time together with a narrow size distribution is obtained. The whole process takes only one day. Effect of first and second aging treatments on nanoparticles size and crystal structure is investigated. Products are characterized by transmission electron microscopy (TEM), X-ray diffraction (XRD), thermogravimetric/differential thermal analysis (TG-DTA) and nitrogen gas absorption (BET).

\section{Experimental}

\subsection{Preparation of titanium dioxide nanoparticles}

Triethanolamine (TEA) and titanium (IV) isopropoxide (TTIP) (both of Merck Co., Germany) were mixed together 
at a molar ratio of 2:1 under argon atmosphere to produce hydrolysis-resistant Ti (IV) complex. Double-distilled deionized water $(18.2 \mathrm{M} \Omega . \mathrm{cm})$ was added to prepare a stock of $\mathrm{Ti}^{4+}\left(0.25 \mathrm{~mol} \mathrm{dm}{ }^{-3}\right)$ homogeneous solution having $9.8 \mathrm{pH}$. The solution was transferred into a Teflon autoclave, sealed with a stainless steel crust and aged at $120^{\circ} \mathrm{C}$ for $18 \mathrm{~h}$ (first aging stage). A viscous to rigid gel was produced. The gel was autoclave-aged at $130,140,150$ and $160^{\circ} \mathrm{C}$ (second aging stage) for up to $12 \mathrm{~h}$ to let nucleation and growth of titania nanoparticles. This converted the gel into a white sol-phase. The sol-phase was centrifuged at 15,000 rpm and washed with ethanol (99.9\%) and distilled water to remove ions present. The process was completed by air drying at $80^{\circ} \mathrm{C}$.

\subsection{Characterization}

X-ray diffraction (XRD) patterns of the synthesized titania powders were obtained by Philips X'Pert High Score Diffractometer using $\mathrm{Cu} \mathrm{K} \alpha$ radiation. Crystallite size was calculated using the well known Scherrer correlation:

$$
D=0 \cdot 9 \lambda / \beta \cdot \cos \theta
$$

The specific surface area and pore volume of the powder was measured by nitrogen absorption (Micromeritics Gemini 2375) using BET equation. Assuming spherical shape for particles, the average particle diameter $(d)$ was calculated using the formula

$$
\left(d_{\mathrm{BET}}=6 / \rho S_{\mathrm{BET}}\right) .
$$

All powders were degassed at $150^{\circ} \mathrm{C}$. Morphology and particle size of the particles were studied by scanning and transmission electron microscopy (Philips EM208). Thermal analysis was performed by PLSTA-1640 thermogravimetrydifferential thermal analysis (TG-DTA) referenced with recalcined alumina at a ramping rate of $5^{\circ} \mathrm{C} \cdot \mathrm{min}^{-1}$ in static air. To identify the gel-phase, it was mixed with $\mathrm{D}_{2} \mathrm{O}$ to form sample solution and then $\mathrm{H}$ and $\mathrm{C}$ liquid-state NMR spectra were recorded (BRUKER 500 DRX-AVANCE).

\section{Results and discussion}

\subsection{Gel phase characterization}

Hydrolysis of titanium (IV) isopropoxide (TTIP) with water proceeds according to the following reaction

$$
\mathrm{Ti}\left(\mathrm{OPr}^{i}\right)_{4}+4 \mathrm{H}_{2} \mathrm{O} \rightarrow \mathrm{Ti}(\mathrm{OH})_{4}+4 \mathrm{C}_{3} \mathrm{H}_{7} \mathrm{OH} .
$$

To control TTIP hydrolysis, triethanolamine (TEA) is added to TTIP. Based on previous reports, addition of TEA to the alcoholic solutions of alkoxides can suppress the hydrolysis reaction resulting in formation of a stable homogeneous
言<smiles>CC(C)O</smiles>
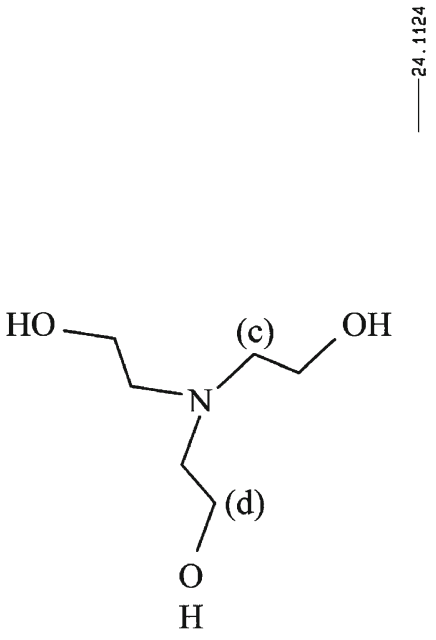

(a)

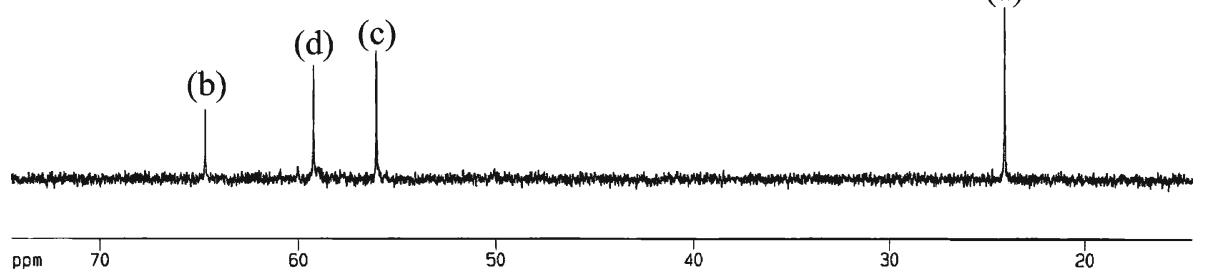

Figure 1. Carbon NMR spectrum of gel-phase. 
non-gel mixture (Park et al 1999). Addition of TEA to TTIP results in formation of large triethanolaminate ligands sitting on Ti atoms through an exothermic reaction (Park et al 1999). An alcohol exchange reaction can occur and the $N$ atom of the alkanolaminato group can bond with Ti to form $\mathrm{Ti}_{3}\left[\left(\mathrm{OC}_{2} \mathrm{H}_{4}\right)_{3} \mathrm{~N}\right]_{4}$ complex (Ban et al 2003)

$$
\begin{aligned}
& \mathrm{Ti}\left(\mathrm{OPr}^{i}\right)_{4}+\mathrm{N}\left(\mathrm{C}_{2} \mathrm{H}_{4} \mathrm{OH}\right)_{3} \\
& \quad \rightarrow \mathrm{Ti}\left(\mathrm{OPr}^{i}\right)-\left(\mathrm{OC}_{2} \mathrm{H}_{4}\right)_{3} \mathrm{~N}+3 \mathrm{C}_{3} \mathrm{H}_{2} \mathrm{OH}
\end{aligned}
$$

or

$$
\begin{aligned}
& 3 \mathrm{Ti}\left(\mathrm{OPr}^{i}\right)_{4}+4 \mathrm{~N}\left(\mathrm{C}_{2} \mathrm{H}_{4} \mathrm{OH}\right)_{3} \\
& \quad \rightarrow \mathrm{Ti}_{3}\left[\left(\mathrm{OC}_{2} \mathrm{H}_{4}\right)_{3} \mathrm{~N}\right]_{4}+12 \mathrm{C}_{3} \mathrm{H}_{7} \mathrm{OH}
\end{aligned}
$$

Carbon and hydrogen NMR spectra of the produced gel are shown in figures 1 and 2, respectively. Based on the results, shift values of the peaks are not observed when using $\mathrm{D}_{2} \mathrm{O}$ as the solvent. After autoclave aging of the gel-phase, both isopropyl alcohol and triethanolamine are freely present without any bond to the Ti ligand. During aging, the $\mathrm{OC}_{2} \mathrm{H}_{4}$ groups are replaced with the $\mathrm{OH}$ groups. A continuous matrix having $\mathrm{Ti}(\mathrm{OH})_{4}$ chemical composition is produced this way:

$$
\begin{aligned}
& \mathrm{Ti}_{3}\left[\left(\mathrm{OC}_{2} \mathrm{H}_{4}\right)_{3} \mathrm{~N}\right]_{4}+12 \mathrm{H}_{2} \mathrm{O} \\
& \quad \rightarrow 3 \mathrm{Ti}(\mathrm{OH})_{4}+4 \mathrm{~N}\left(\mathrm{C}_{2} \mathrm{H}_{4} \mathrm{OH}\right)_{3} .
\end{aligned}
$$

\subsection{XRD results}

Figure 3 shows XRD pattern of the product after aging for $12 \mathrm{~h}$ at $130^{\circ} \mathrm{C}$ (the second aging stage). The pattern fits well with the standard anatase phase (JCPDS, No. 21-1272). No

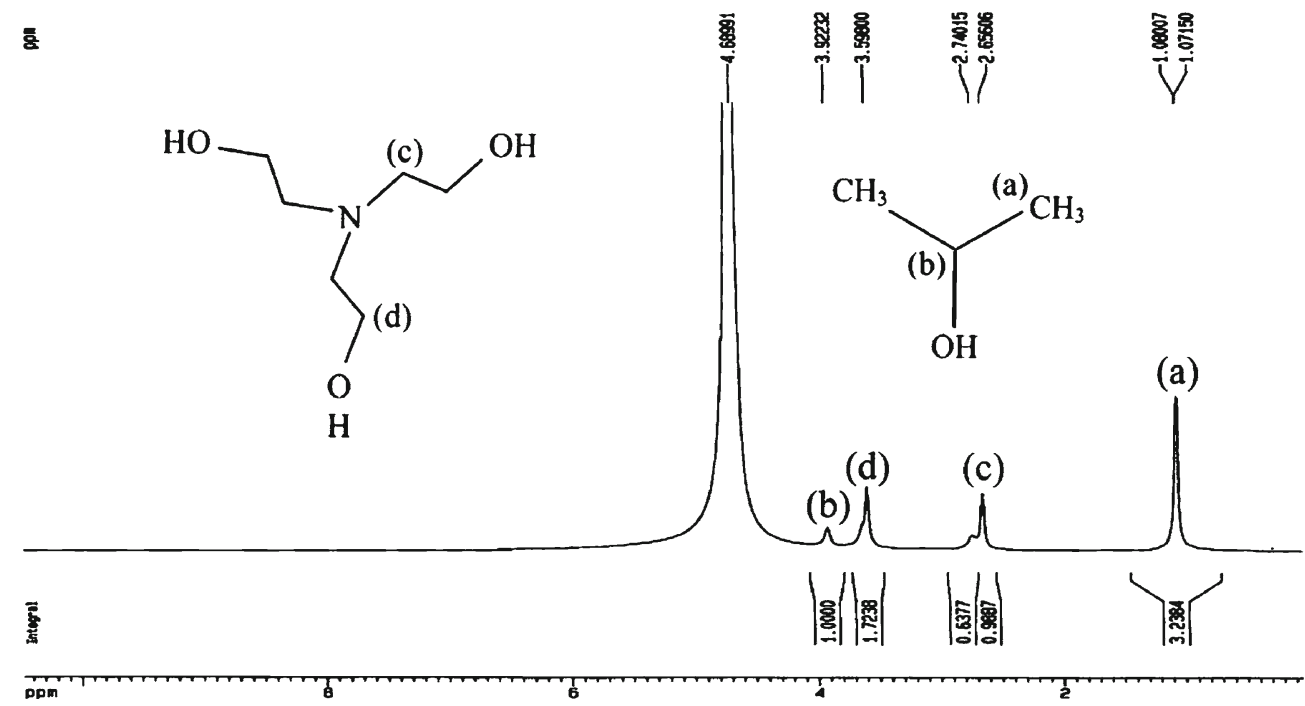

Figure 2. Hydrogen NMR spectrum of gel-phase.

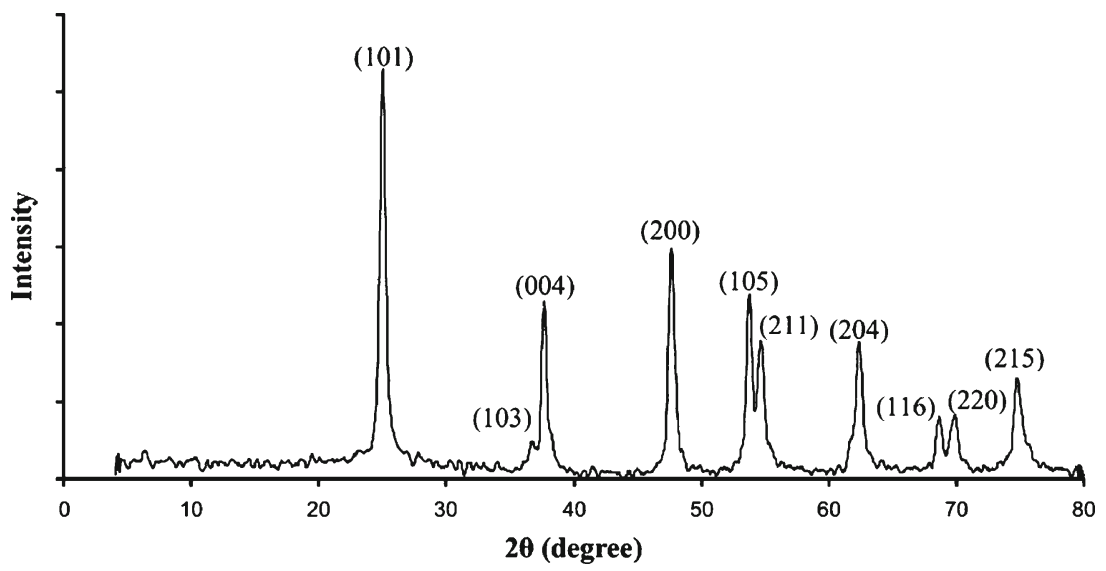

Figure 3. XRD pattern of titania powder produced after aging for $12 \mathrm{~h}$ at $130^{\circ} \mathrm{C}$ (second aging stage). 
rutile or brookite peaks are observed. This indicates presence of crystalline anatase nanopowder.

\subsection{Effect of aging duration}

Figure 4 shows XRD patterns of the products obtained after aging at $130^{\circ} \mathrm{C}$ for different durations (the second aging stage). These patterns illustrate pure anatase crystalline structure in all $\mathrm{TiO}_{2}$ nanopowders aged at $130^{\circ} \mathrm{C}$. This feature can be attributed to the hydrothermal reactions that take place during the gel-sol process.

Although the X-ray diffraction peaks of the synthesized titania gel-sol powders increase with the aging duration, they all seem to have the same principal configuration. This indicates a mere crystallite size increase of the nanopowders. The data calculated from (101) reflections indicate that the crystallite size increases from $7-11 \mathrm{~nm}$ when the aging duration increases from 4-8 h.

\section{$3.4 \quad N_{2}$ adsorption}

The $\mathrm{N}_{2}$ adsorption of BET plot of the produced powders is given in figure 5. Surface area and pore volume of the titanium dioxide powders aged at $130^{\circ} \mathrm{C}$ are summarized in table 1 . The results show that the gel-sol process produces large surface areas. This seems due to both nucleation and controlled growth of the particles. Specific surface area of the powders aged at $130^{\circ} \mathrm{C}$ for $4 \mathrm{~h}$ is $220 \mathrm{~m}^{2} / \mathrm{g}$ which corresponds to $\sim 7 \mathrm{~nm}$ average particle sizes. This specific surface area reduces to $155 \mathrm{~m}^{2} / \mathrm{g}$, when the aging time increases to $12 \mathrm{~h}$. After aging for $8 \mathrm{~h}$, the average particle size becomes $\sim 9 \mathrm{~nm}$ while after $12 \mathrm{~h}$, an average particle size of $10 \mathrm{~nm}$ is

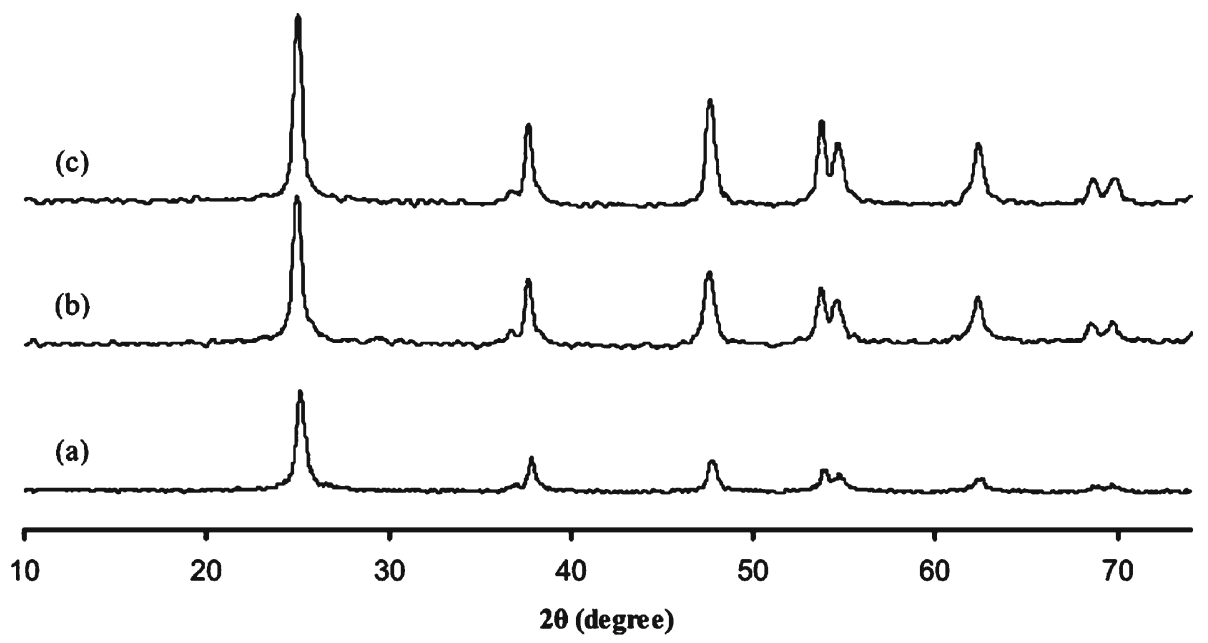

Figure 4. XRD pattern of titanium dioxide aged at $130^{\circ} \mathrm{C}$ for (a) 4 , (b) 8 and (c) $12 \mathrm{~h}$.

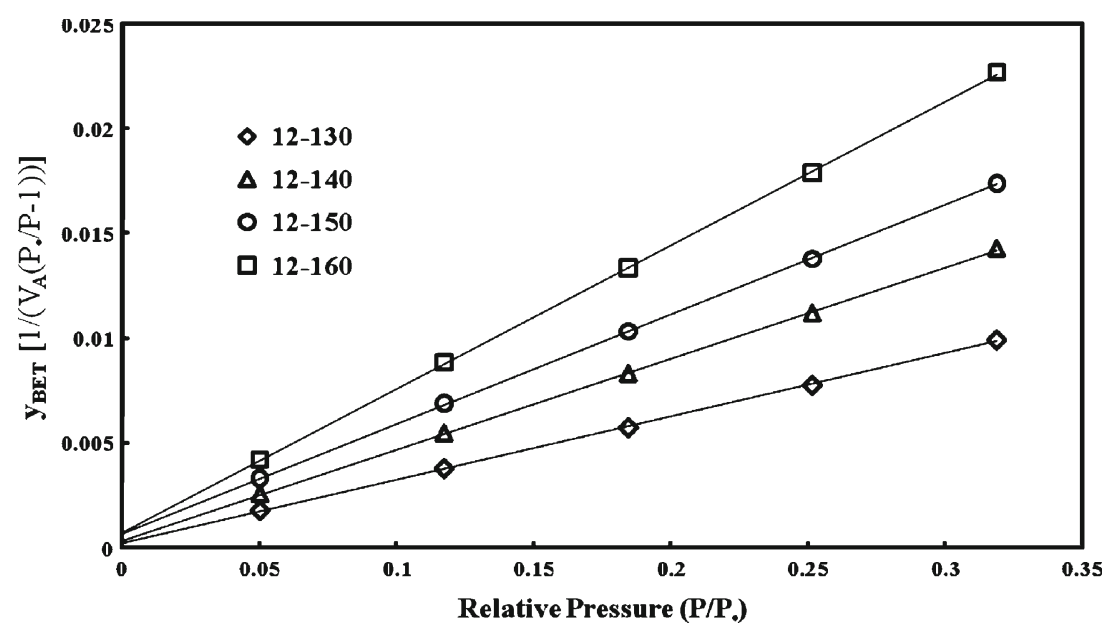

Figure 5. $\mathrm{N}_{2}$ adsorption of BET plot of titanium dioxide powders heat treated at 130, 140,150 and $160^{\circ} \mathrm{C}$ for $12 \mathrm{~h}$. 
Table 1. Effect of second-stage aging time and temperature on crystallite size, surface area and pore volume of anatase particles.

\begin{tabular}{|c|c|c|c|c|c|}
\hline \multicolumn{6}{|c|}{ Size specifications } \\
\hline & & XRD & \multicolumn{3}{|c|}{ BET } \\
\hline \multicolumn{2}{|c|}{ Aging conditions } & \multirow{2}{*}{$\begin{array}{c}\text { Crystallite size, } \\
d_{101}(\mathrm{~nm})\end{array}$} & \multirow{2}{*}{$\begin{array}{c}\text { Surface } \\
\text { area }\left(\mathrm{m}^{2} / \mathrm{g}\right)\end{array}$} & \multirow{2}{*}{$\begin{array}{l}\text { Average particle } \\
\text { size, } d_{\mathrm{BET}}(\mathrm{nm})\end{array}$} & \multirow{2}{*}{$\begin{array}{c}\text { Total pore } \\
\text { volume }\left[\mathrm{cm}^{3} / \mathrm{g}\right.\end{array}$} \\
\hline$\overline{\Delta t(\mathrm{~h})}$ & $T\left({ }^{\circ} \mathrm{C}\right)$ & & & & \\
\hline 4 & 130 & 7 & 220 & 7 & 0.2453 \\
\hline 8 & 130 & 10 & 169 & 9 & $0 \cdot 2409$ \\
\hline 12 & 130 & 12 & 155 & 10 & $0 \cdot 2320$ \\
\hline 12 & 140 & 14 & 102 & 15 & $0 \cdot 1790$ \\
\hline 12 & 150 & 19 & 85 & 18 & $0 \cdot 2014$ \\
\hline 12 & 160 & 21 & 64 & 24 & $0 \cdot 1584$ \\
\hline
\end{tabular}

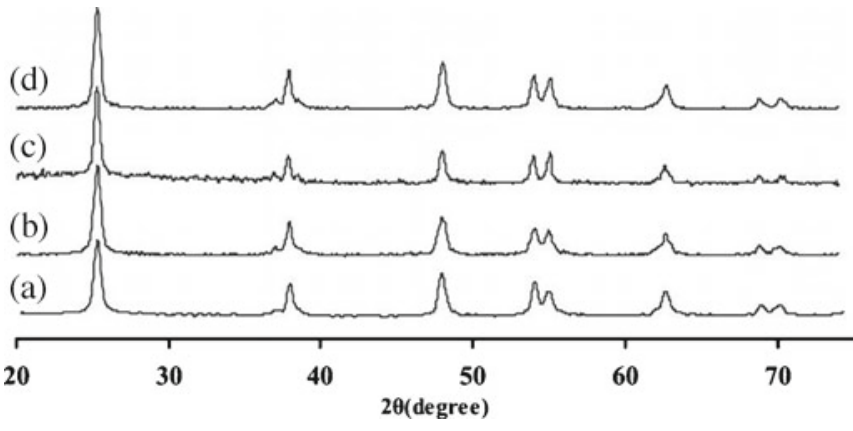

Figure 6. XRD patterns of titanium dioxide powders aged for $12 \mathrm{~h}$ at (a) 130 , (b) 140 , (c) 150 and (d) $160^{\circ} \mathrm{C}$.

obtained. Further increase in the aging time results in reduction of the growth rate of particles due to decrease of $\mathrm{Ti}^{4+}$ ion concentration.

\subsection{Effect of aging temperature}

Figure 6 illustrates XRD patterns of the titania nanopowder after $12 \mathrm{~h}$ aging at different temperatures (the second aging stage). A comparison of the patterns shows that temperature has no significant effect on the crystal structure of the produced anatase nanoparticles. XRD and $\mathrm{N}_{2}$ absorption results are summarized in table 1. Although all powders have relatively large surface areas, high temperature aging still plays a significant role by increasing the growth rate. Increasing temperature from 130 to $160^{\circ} \mathrm{C}$ reduces the surface area of the powders from 155 to $64 \mathrm{~m}^{2} / \mathrm{g}$ and increases the mean particle size of the samples from 10-24 nm.

\subsection{TEM}

Figure 7 illustrates transmission electron bright field image of the nanoparticles aged at $130^{\circ} \mathrm{C}$ for $8 \mathrm{~h}$ and $150^{\circ} \mathrm{C}$ for $12 \mathrm{~h}$. It indicates uniform, almost spherical and nearly equi-sized nanoparticles shapes. Uniformity and narrow size distribution of the particles both indicate a successful gel-sol operation.

The gel phase operates here like a medium reserving $\mathrm{Ti}^{4+}$ for supersaturation suppression and extensive nucleation prevention. No preferable nucleation sites exist due to the homogenous thermodynamic equilibrium. Widespread nucleation can, thus, randomly occur at all points of the gel phase. The gel-phase acts as an anticoagulant substance which fixes the particles in the medium (Sugimoto et al 1997). Nanoparticles, hence, acquire particle sizes between 12 and $25 \mathrm{~nm}$.

Transmission electron micrograph of the nanoparticles shown in figure 7 indicates excellent agreement with the data obtained from BET and XRD tests (table 1 and figures 3-6).

\subsection{TG-DTA}

TG-DTA results shown in figure 8 indicate a weight loss of $\sim 4 \%$ below $100^{\circ} \mathrm{C}$. This loss corresponds to physical or chemical desorption of such species as $\mathrm{H}_{2} \mathrm{O}$ and $\mathrm{CO}_{2}$ (Yanqing et al 2000). From 100 to $300^{\circ} \mathrm{C}$, a weight loss of about $6 \%$ is recorded. This loss can be attributed to removal of such organic species like unhydrolyzed isopropoxide ligands bond to titanium (Hafizah and Sopyan 2009). Above $400^{\circ} \mathrm{C}$, DTA curve shows a large convex appearance indicating slow growth of titania. The absence of a sharp peak in DTA curve indicates that no phase transformation remarkably occurs during the heating process (Hsiang and Lin 2004). It is well known that the brookite and anatase both belong to metastable phase.

Since surface free energy and surface stress have both significant roles on the phase stability of the nanocrystalline system, the particle size exerts substantial effect of production and endurance of a specific polymorph in the synthesized nanopowder system. Thermodynamic analysis indicates that below $14 \mathrm{~nm}$, anatase is more stable than rutile phase (Zhang and Banfield 1998, 2000; Li et al 2007). Anatase is hence 
the most thermodynamically stable phase, when nanocrystallites have $<11 \mathrm{~nm}$ size. For crystallite sizes between 11 and $35 \mathrm{~nm}$, Brookite is the most stable phase (Zhang and Banfield 1998, 2000; Li et al 2007). At sizes > $35 \mathrm{~nm}$, rutile is the most stable phase (Zhang and Banfield 1998, 2000; Li et al 2007). These results are also empirically confirmed throughout this research

\section{Conclusions}

High crystalline titanium dioxide nanoparticles with pure anatase crystalline structure are produced via a lowtemperature gel-sol method. Superior gel-phase characteristics and hydrothermal conditions results in production of nanoparticles having large surface area and small mean
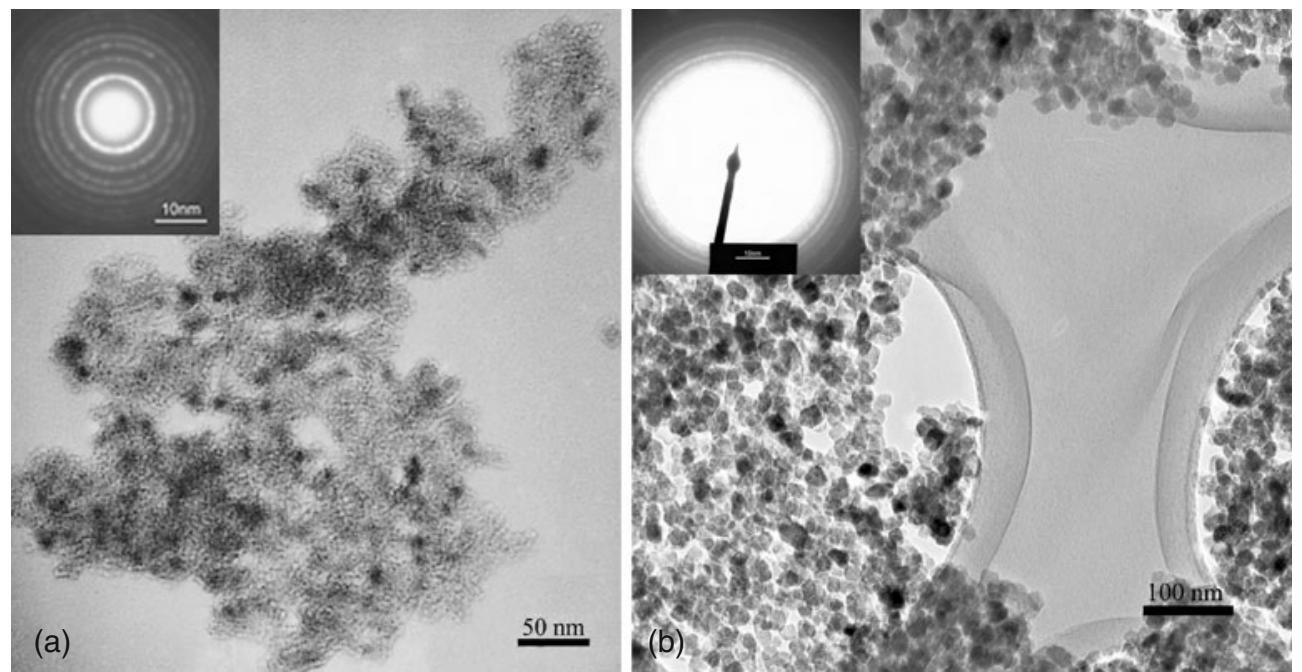

Figure 7. Bright field TEM images of nanoparticles aged at (a) $130{ }^{\circ} \mathrm{C}$ for $8 \mathrm{~h}$ and (b) $150{ }^{\circ} \mathrm{C}$ for $12 \mathrm{~h}$. Insets are diffraction patterns of powders.

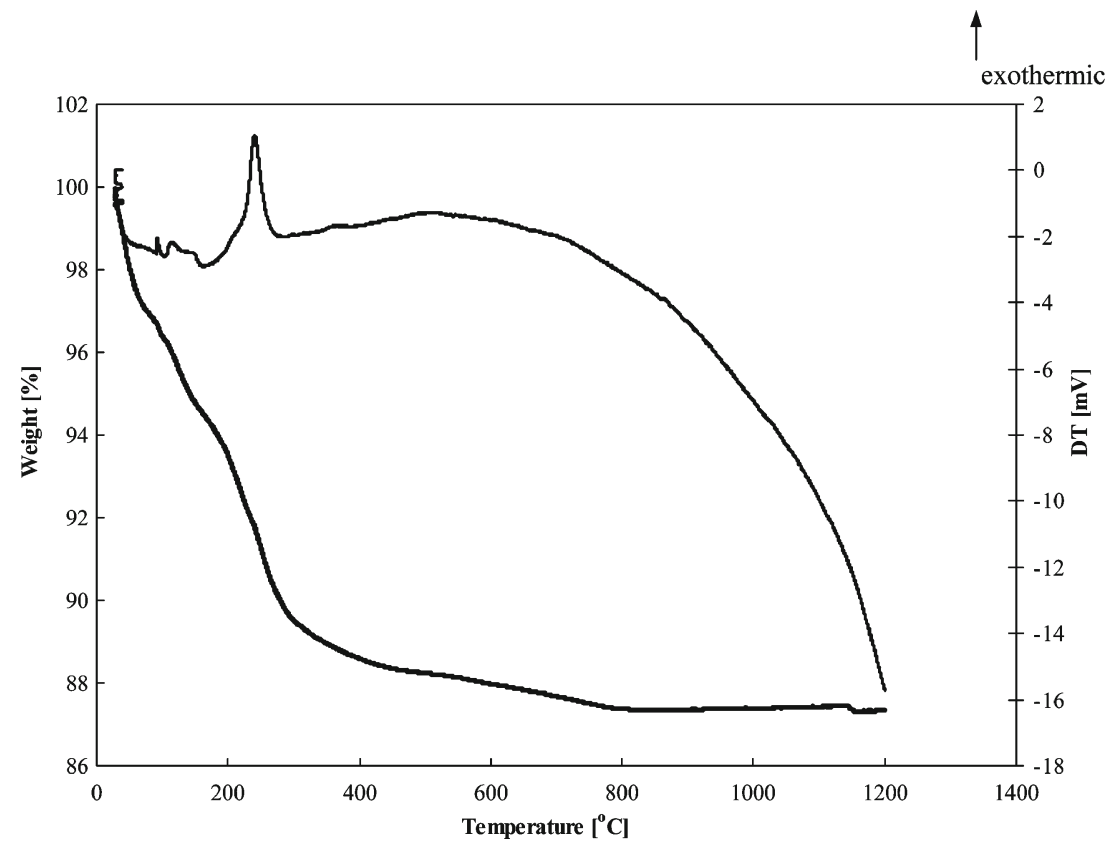

Figure 8. TG-DTA curves of titania powder aged at $130^{\circ} \mathrm{C}$ for $12 \mathrm{~h}$ (second aging stage). 
particle sizes. Nanoparticles produced by the gel-sol method are uniform, homogenous and highly stable with $\sim 7$ to $24 \mathrm{~nm}$ average diameter. Time and temperature of aging do not affect the crystallite structure, but they increase the particulate size and decrease the specific pore volume of the powder.

\section{References}

Almquist C B and Biswas P 2002 J. Catal. 212145

Ban T, Ohya Y and Takahashi Y 2003 J. Sol-Gel Sci. Technol. 27 363

Byrappa K and Adschiri T 2007 Prog. Cryst. Growth 53117

Cappelletti G, Bianchi C L and Ardizzone S 2008 Appl. Catal. BEnviron. 78193

Chen X and Mao S S 2007 Chem. Rev. 1072891

Diebold U 2003 Surf. Sci. Rep. 4853

Fujishima A, Rao T N and Tryk D A 2000 J. Photochem. Photobiol. C1 1

Hafizah N and Sopyan I 2009 Int. J. Photoenergy 2009962783

Hoffmann M R, Martin S T, Choi W and Bahnemann D W 1995 Chem. Rev. 9569

Hosokawa M, Nogi K, Naito M and Yokoyama T 2007 Nanoparticle technology handbook (Oxford: Elsevier) pp 509-515
Hsiang H I and Lin S C 2004 Mater. Sci. Eng. A380 67

Itoh H and Sugimoto T 2003 J. Colloid. Interf. Sci. 265283

Kim S J, Park S D and Jeong Y H 1999 J. Am. Ceram. Soc. 82927

Li S, Jiang Z H and Jiang Q 2007 Mater. Res. Bull. 433149 doi:10.1016/j.materresbull.11.003

Park Y I, Kim C E and Lee H W 1999 J. Sol-Gel Sci. Technol. 14 149

Phonthammachai N, Chairassameewong T, Gulari E, Jamieson A M and Wongkasemjit S 2003 Microporous Mesoporous Mater. 66 261

Sivakumar S, Pillai P K, Mukundan P and Warrier K G K 2002 Mater. Lett. 57330

Song K C and Pratsinis S E 2001 J. Am. Ceram. Soc. 8492

Sugimoto T and Sakata K 1992 J. Colloid. Interf. Sci. 152587

Sugimoto T, Okada K and Itoh H 1997 J. Colloid Interf. Sci. 193 140

Sugimoto T, Okada K and Itoh H 1998 J. Dispers. Sci. Technol. 19 143

Tang Z, Zhang J, Cheng Z and Zhang Z 2002 Mater. Chem. Phys. 77314

Yanqing Z, Erwei S, Suxian C, Wenjun L and Xingfang H $2000 \mathrm{~J}$. Mater. Sci. Lett. 191445

Zhang H and Banfield J F 1998 J. Mater. Chem. 82073

Zhang H and Banfield J F 2000 J. Phys. Chem. B104 3481 